\title{
Automated fault clearance using fault current limiter in primary distribution system
}

\author{
Shailja Patwa ${ }^{1,}$ Dr. A. Trivedi ${ }^{2}$ \\ ${ }^{1}$ M.E. HVPS-IV sem., Jabalpur Engineering College, Electrical Engineering Department \\ ${ }^{2}$ Reader, Jabalpur Engineering College, Electrical Engineering Department, Jabalpur, India
}

\begin{abstract}
This paper presents the development, simulation results, and the application of current limiter in fault analysis of primary distribution system. A large current flows during the fault, short-circuit or any other abnormal condition in power system. There is always a need to use some kind of external device to limit the peak value of the fault current. Distribution systems across most parts of the globe are highly radial in nature. As loads are gradually increased on a particular distribution system, a higher operating current state leading to increased fault current levels is attained. Hence, the relay co-ordination is disturbed and equipments such as feeders and circuit breakers need to be replaced with higher rating so that they can handle the new currents often leading to expensive retrofit costs.

The use of fault current limiter $(F C L)$ is proposed to remove the effects of high current levels on a distribution system. Results from simulation studies are investigated and compared to a healthy condition.
\end{abstract}

Keywords: Fault Current Limiting, High Temperature Superconducting, Transient Recovery Voltage, Shortcircuit Currents, High Voltage.

\section{INTRODUCTION}

The demand for electric power is growing and electrical power networks are becoming more interconnected. This is a trend in many countries of the world and it is caused by increased customer requirements and advanced technological improvements. In order to meet the ever-increasing energy demand, the integration of new power sources in the grid is necessary. The short-circuit current withstand capability of system components are often exceeded when a new power plant is connected with conventional cables to an existing grid, due to the increase of the short-circuit current contribution. It is also a big challenge to increase the amount of generated power due to bottlenecks such as voltage fluctuations, high fault current levels and reactive power.

Devices and techniques such as circuit breakers, fuses, aircore reactors, employing fault current limiters (FCLs) have been applied to limit the available short-circuit currents [1]. Due to the progress that has been made in the development of superconducting materials, it is possible to commercialize FCL. This technology has many advantages because it is possible to limiting the short-circuit current and having very low energy losses. The FCL limits fault currents, without energy losses, during normal operation due to a smart non-linear cable resistance. Under fault conditions the non-linear resistance of the cable is inserted into the power network to limit the short-circuit current. The transition from the superconducting to the normal-state, the so-called quench, takes place automatically [2].

\section{WORKING AND DESIGN OF FAULT CURRENT LIMITER}

Fault current limiters are devices that are designed to separate parts of the network when a fault occurs. They are fast operating devices that commence operation within the first few milliseconds after a fault, and limit the first peak of the fault current to acceptable levels.

Fault current limiters consist of current limiting fuses operated in parallel with exposable links. The exposable link may be constructed from a brass tube fitted with an explosive charge. The tube is appropriately fissured to control its bursting performance, and is employed to carry the normal load current of the device. The construction and operating characteristics of this type of FCL are described in [1]. An alternative form of exposable link consists of a segmented copper bar, again appropriately fissured, which separates into a number of segments, again by the triggering of an explosive charge. This type of FCL is illustrated in [2].

On detection of a fault meeting the tripping criteria, the charge is detonated separating the exposable link, thus leaving only the current limiting fuse in the circuit. The fuse then operates separating the two parts of the network, effectively limiting the first peak of the fault current to that generated by the source on the faulted part of the network plus the let through current of the fuse. The principle of operation of current limiting fuses is 
well known and will not be expanded on here. It is understood, however, that the detailed design aspects of current limiting fuses for this application are somewhat different to those used for typical applications. In particular, for this application the rating of the fuse element is significantly smaller than the normal load current expected to be carried by the FCL, thus ensuring rapid operation.

\section{USE OF FAULT CURRENT LIMITERS}

A typical representation of an electric network is shown in figure 1. If any unforeseen accident happens which leads to a fault a lot of current will flow. The amount of current is restricted by the internal impedance of the generator and the line between the generator and fault. Usually the internal impedance is very low so the magnitude of the fault current is very large. The large fault current will initiate the operation of the circuit breaker (CB) and the $\mathrm{CB}$ will break the circuit. Usually the $\mathrm{CB}$ breaks the circuit at the zero crossing of the current wave.

The location of FCL to be carefully selected so that the fault current can be restricted within an optimum value. The FCL will limit the fault current which will allow the lower rating CBs to be used in the system. Now as the FCL is always there in the system, under normal condition the system should not observe the presence of the FCL. At the same time the FCL should response almost instantaneously at fault.

\section{MODELLING APPROACH}

The postulated cause of the spurious operations was transients interfering with the di/dt sensing. Review of [2] corroborates this theory, and hence a time domain model of the system was required to analyse the system in the first half cycle after fault initiation. References [3] and [4] provided some useful information on modelling of current limiting fuses, and after reviewing these it was decided to model the FCL using the Matlab simulation.

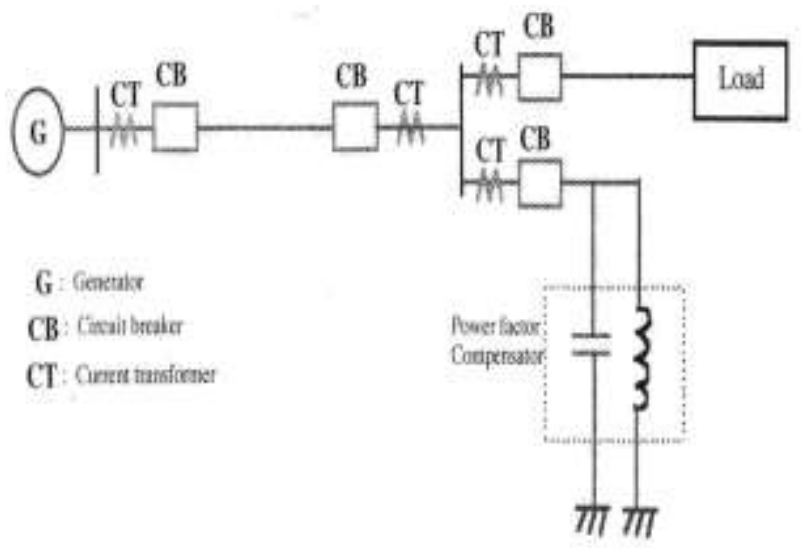

Figure 1. A typical electric power network

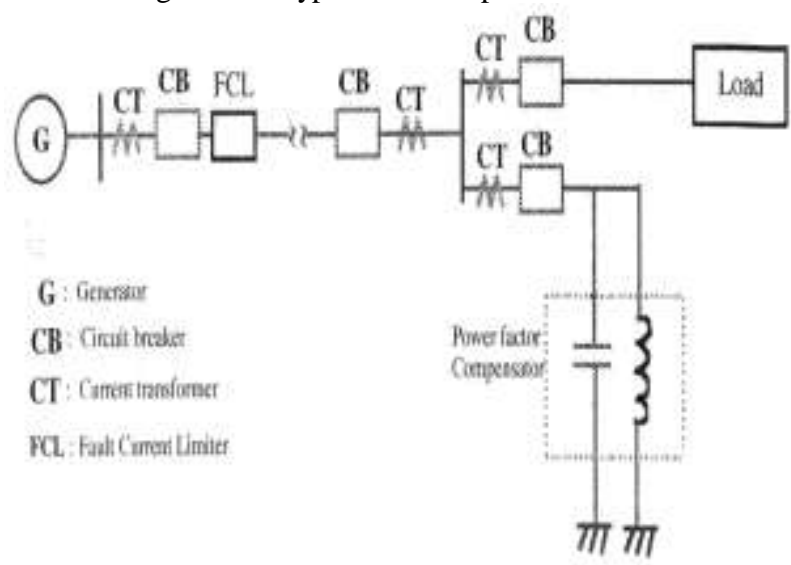

Figure 2. The electric power network with FCL in use 


\section{TRIPPING CRITERIA}

The tripping criteria were fairly complex, and are given below for FCL :

i) the instantaneous value of the current through FCL must be between nominated high and low gateway settings ii) the absolute value of the time derivative of the current through the FCL must be above the nominated di/dt trip setting for the FCL

iii) the time derivative of the summation of the incomer current and the FCL current is above its trip setting, and iv) the sign of all of the above is identical, and

v) the instantaneous value of the summation of the incomer current and the FCL current is above its trip setting. If the above are satisfied, then operation of the FCL is required to occur.

\section{FAULT ANALYSIS ON DISTRIBUTION FEEDERS}

For conventional distribution feeders, the substation is the only source of power, and since the substations are usually away from big generation units, the fault current transients do not have the initial high "subtransient component" that one can see in a fault current of the transmission system. Therefore, the fault current is usually approximated by its steady-state value. Thus, the feeder can be represented by a steady-state model, in which the substation is represented by a Thevenin equivalent (i.e., a voltage source behind the source impedance), and the lines are represented by their series impedances. The loads are usually neglected, but if needed, loads can be represented by their equivalent impedances. The corresponding equivalent circuit can then be analyzed by using the nodal equations (1) where is the node admittance matrix, is the voltage at each node, and is the current injected at each node. This model can be for equivalent single phase or can be extended for three-phase analysis especially to include the mutual coupling effects [12], [13].

If there are conventional generators on the feeder, the above feeder model can be extended easily by using the simple Thevenin equivalent models for the generators [12]. For inverter interfaced DGs, the same technique cannot be applied, since as it will be illustrated below, the inverter alters the generator response considerably. Therefore, a new approach is needed in order to incorporate IIDGs into the fault analysis.

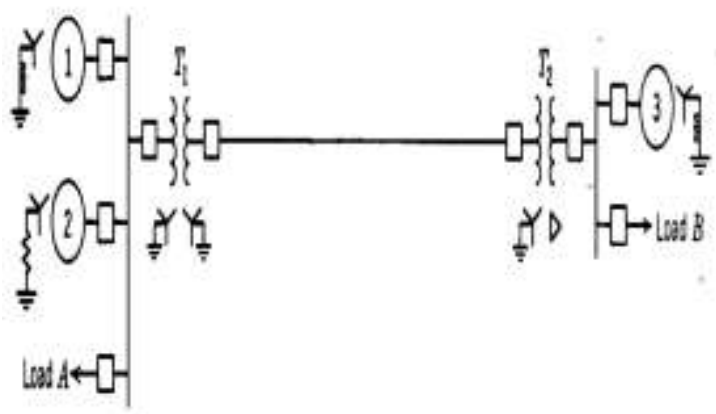

Figure 1- Single line diagram of an electric power system

Figure1 shows a small power system. In this case connections of generator and transformer windings, as well as the method of grounding the neutral are indicated.

By simulation initially a healthy model is simulated and results are displayed.

Then L-G fault is created at some distant and result of fault current and voltage are recorded . then location of the fault is changed and corresponding fault current .

A distribution line of 60 kilo meter has created. Since fault detection will be apply only on primary distribution system. That's why the voltage rating is between $33 \mathrm{KV}$ to $11 \mathrm{KV}$. Frequency is $50 \mathrm{HZ}$.

\section{TEST RESULT}

The table 1 shows the required source condition for the fault detection in primary distribution system .

TABLE 1

Required source condition for the fault detection in primary distribution system

\begin{tabular}{|l|l|}
\hline Line length & $60 \mathrm{~km}$ \\
\hline Voltage & $33 \mathrm{kv}-11 \mathrm{kv}$ \\
\hline frequency & $50 \mathrm{hz}$ \\
\hline Time cycle & 0.01 \\
\hline Type of fault & Line to ground fault \\
\hline
\end{tabular}

Table 2 shows the peak value of voltage at healthy condition (per unit value) and peak value of current at healthy condition (per unit value) 
TABLE 2

peak value of voltage at healthy condition (per unit value) and peak value of current at healthy condition (per unit value

\begin{tabular}{|l|l|l|}
\hline $\begin{array}{l}\text { Time } \\
\text { Cycle(sec) }\end{array}$ & $\begin{array}{l}\text { Peak value of } \\
\text { Voltage At } \\
\text { Healthy Condition } \\
\text { (Per Unit Value) } \\
\text { Vb }\end{array}$ & $\begin{array}{l}\text { Peak Value Of } \\
\text { Current At } \\
\text { Healthy Condition } \\
\text { (Per Unit Value) } \\
\text { Ib }\end{array}$ \\
\hline 0.01 & 0.0533 & 0.8061 \\
\hline 0.02 & -0.0578 & -0.063 \\
\hline 0.03 & 0.0529 & 1.1035 \\
\hline 0.04 & -0.0447 & -0.1727 \\
\hline 0.05 & 0.0509 & 0.9992 \\
\hline 0.06 & -0.0415 & -0.1812 \\
\hline 0.07 & 0.0506 & 0.9294 \\
\hline 0.08 & -0.0464 & -0.2508 \\
\hline 0.09 & 0.068 & 0.9206 \\
\hline 0.1 & -0.0625 & -0.0693 \\
\hline
\end{tabular}

Table 3 shows the Fault detection of peak value of voltage at faulty situation and peak value of current at fault .

Table $-\mathbf{7 . 3}$

peak value of voltage (per unit value) and peak value of current (per unit value) at faulty condition at blue phase

\begin{tabular}{|c|c|c|}
\hline Time Cycle(sec) & $\begin{array}{l}\text { Peak value of Voltage At faulty Condition } \\
\text { (Per Unit Value) V }\end{array}$ & $\begin{array}{c}\text { Peak Value Of Current At faulty } \\
\text { Condition (Per Unit Value) I }\end{array}$ \\
\hline $\mathbf{0 . 0 1}$ & $\mathbf{0 . 1 5 6 5}$ & $\mathbf{0 . 8 9 4 3}$ \\
\hline $\mathbf{0 . 0 2}$ & $\mathbf{0}$ & $\mathbf{3 . 9 5 9}$ \\
\hline $\mathbf{0 . 0 3}$ & $\mathbf{0}$ & $\mathbf{- 4 . 6 1 3}$ \\
\hline $\mathbf{0 . 0 4}$ & $\mathbf{0}$ & $\mathbf{3 . 2 2 7}$ \\
\hline $\mathbf{0 . 0 5}$ & $\mathbf{0}$ & $\mathbf{- 7 . 9 5 2}$ \\
\hline $\mathbf{0 . 0 6}$ & $\mathbf{0}$ & $\mathbf{- 4 . 7 1 9}$ \\
\hline $\mathbf{0 . 0 7}$ & $\mathbf{0}$ & $\mathbf{3 . 5 2 8}$ \\
\hline $\mathbf{0 . 0 8}$ & $\mathbf{0}$ & $\mathbf{- 7 . 3 5 7}$ \\
\hline $\mathbf{0 . 0 9}$ & $\mathbf{0}$ & $\mathbf{0 . 9 2 6}$ \\
\hline $\mathbf{0 . 1 0}$ & $\mathbf{0 . 1 5 4}$ & $\mathbf{0 . 0 8 9 3}$ \\
\hline
\end{tabular}

In Figure 3, the results of pre fault has been given. The above part shows the voltage waveform of R,Y,B phase an the below part shows the current waveform of R,Y,B phase.

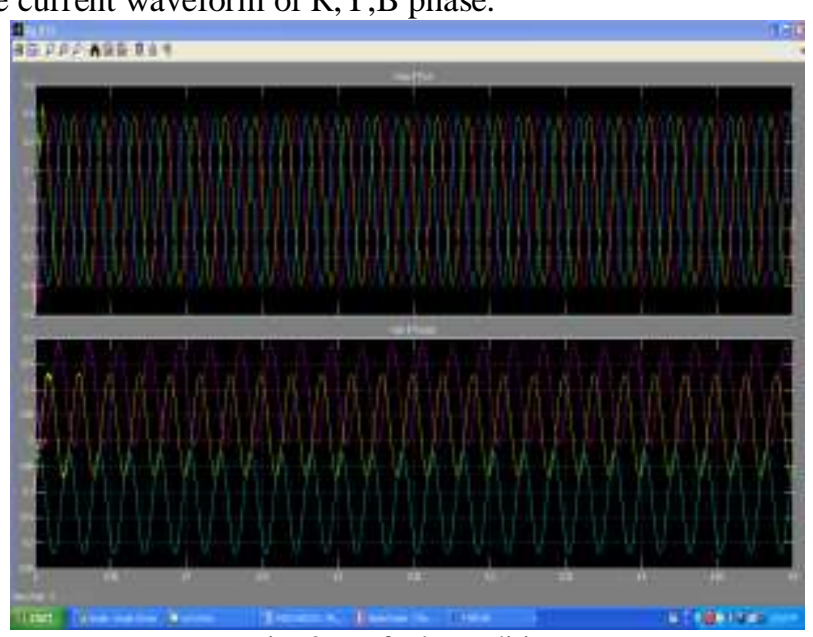

Fig. 3 Pre fault condition

In Figure 4, the results about Single-Phase to Ground Fault has been given. By this we can see the waveform of voltage and current at faulty condition. The fault is in blue phase 


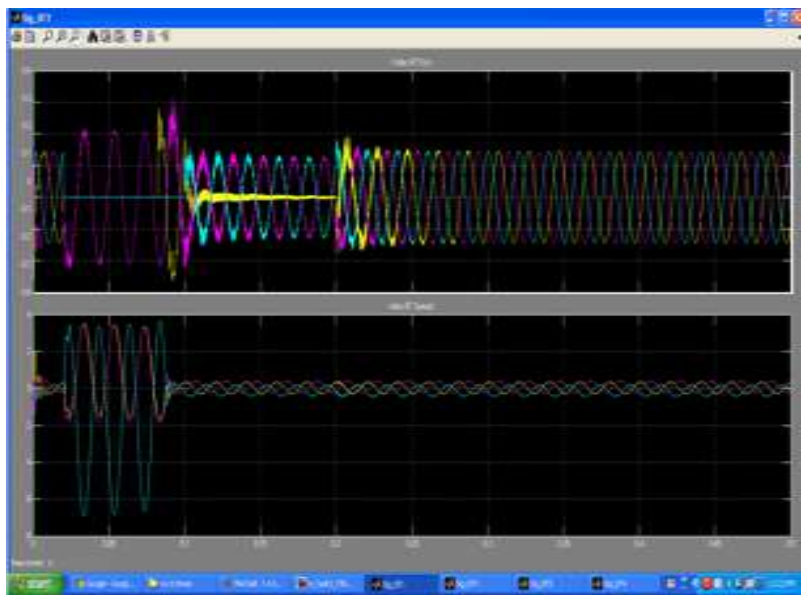

Fig.4- Fault occurrence in blue phase

In the fig.-5, The result about the post fault condition and the application of current limiter given .By this we can see the waveform of voltages and current.

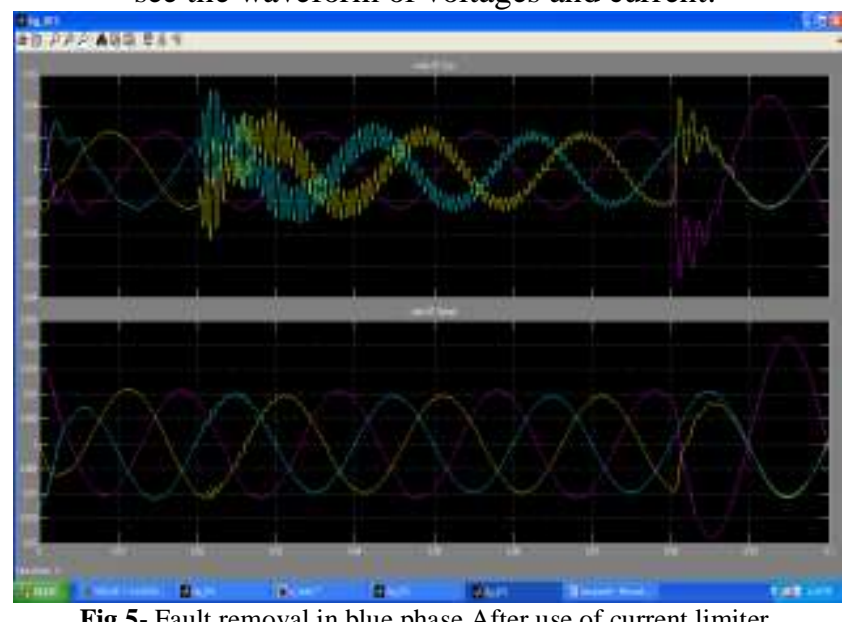

Fig.5- Fault removal in blue phase After use of current limiter

In the fig.-6, The result about the post fault condition and the application of circuit breaker given .By this we can see the waveform of voltages and current

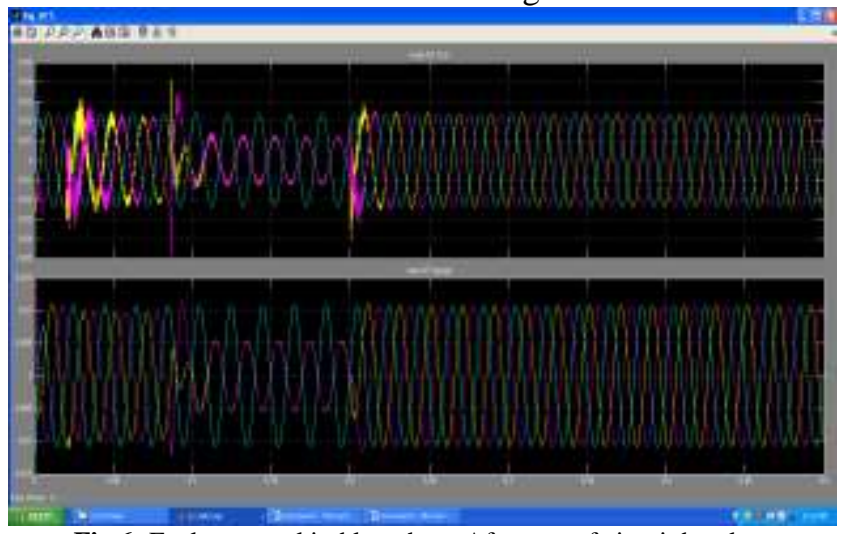

Fig.6- Fault removal in blue phase After use of circuit breaker

\section{COMPARATIVE RESULT WITH AND WITHOUT FAULT CURRENT LIMITER}

The amount of current is restricted by the internal impedance of the generator and the line between the generator and fault. Usually the internal impedance is very low so the magnitude of the fault current is very large. The large fault current will initiate the operation of the circuit breaker (CB) and the CB will break the circuit. Usually the CB breaks the circuit at the zero crossing of the current wave. Figure 8 shows the use of FCL. The location of FCL to be carefully selected so that the fault current can be restricted within an optimum value. The FCL will limit the fault current which will allow the lower rating CBs to be used in the system. Now 
as the FCL is always there in the system, under normal condition the system should not observe the presence of the FCL. At the same time the FCL should response almost instantaneously at fault.

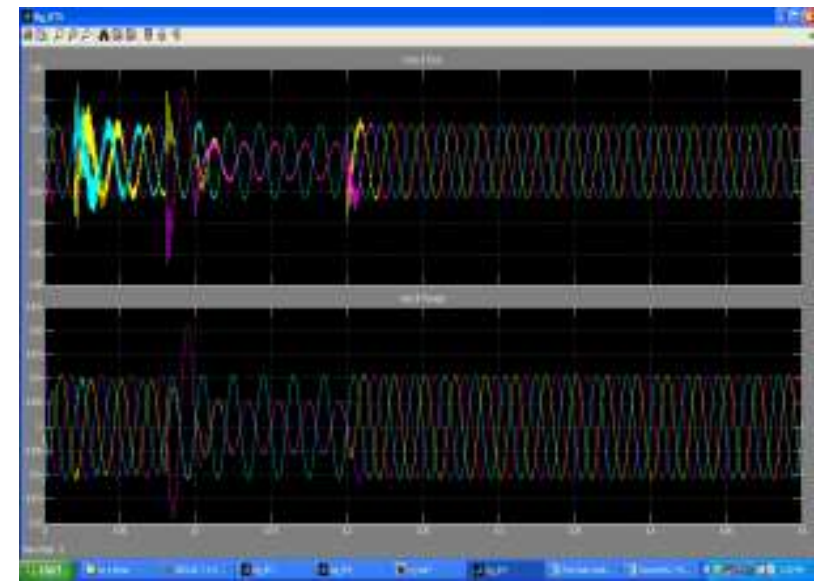

Fig.7 - fault removal after Use of circuit breaker

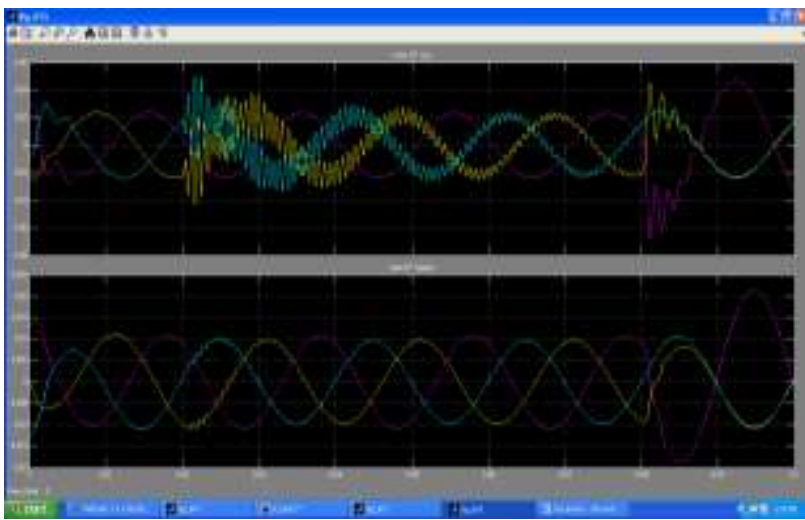

Fig. 8 -fault removal by use of current limiter

\section{CONCLUSION}

'As it is evident now, FCL technology is still under development and at its infancy. a comprehensive and up-todate literature review of the major kinds of fault current limiters that have been simulated, lab tested and even installed in the field. Results regarding advanced protection, adoption of FCL, and upgrading activities, that was conducted as a part of the project is also reported. Current status of the FCL technology along with potential issues and concerns are discussed. proposed some of the techniques to model a behavioral fault current limiter in the MATLAB environment. This includes synthesizing of fault detection algorithms, FCL activation, operation and timing and their respective algorithmic implementations.Future directions of this work include to run simulation studies with two or more $\mathrm{FCL}(\mathrm{s})$ in a larger distribution system, and monitor its effect on current mitigation, relay co-ordination and possible mis-operation.

\section{Reference}

[1] S.Kirshna and K.R.Padiyar" Transient stability assessment using artificial neural network”. Industrial Technology 2000, Proceeding of IEEE International conference on,Vol.1,2000,pp 627-632

[2] K. Warwick, A. Ekwure, R. Aggarwal, Artificial Intelligence Techniques in Power Systems, IEE Power Engineering Series 22, Bookcratt Printed, pp. 17-19, 1997

[3] G. Rolim, J.G. Zurn, Interpretation of Remote Backup Protection for Fault Section Estimation by a Fuzzy Exper System, IEEE PowerTech Conference, pp. 312-315, June 2003.

[4] R. Lukomski, K. Wilkosz, Power System Topology Verification Using Artificial Neural Network Utilization of Measurement Data, IEEE PowerTech Conference, pp. 180-186, July 2003.

[5] T.T. Nguyen, Neural Network Load Flow, IEEE Trans. Of Distribution, Generation and Transmission Conference, pp. 51-58, January 1999.

[6] J. Zhu, D. Lubkeman, A. Girgis, 1997, “ Automated Fault Location and Diagnosis on Electric Power Distribution Feeders”, IEEE Trans. Power Delivery, Vol.12, pp. 801-809.

[7] Das R., Sachdev M., Sidhu T. "A fault locator for radial subs transmission and distribution lines" IEEE Power Engineering Society Summer Meeting, Seattle, 2000.

[8] K.K. Li, L.L. Lai, A.K. David, 2000, " Application of Artificial Neural Networks in Fault Location Technique", ProceedingDPRT 2000 , pp. $226-231$ 